\title{
Microstructural Features of Some Low Water/Solids, Silica Fume Mortars Cured at Different Temperatures
}

Paul E. Stutzman

James R. Clifton

Building and Fire Research Laboratory

Gaithersburg, Maryland 20899

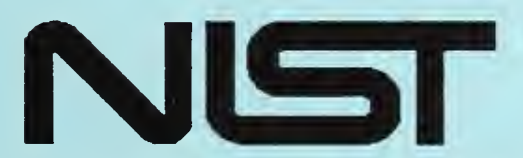

United States Department of Commerce

Technology Administration

National Institute of Standards and Technology 



\section{Microstructural Features of Some Low Water/Solids, Silica Fume Mortars Cured at Different Temperatures}

Paul E. Stutzman

James R. Clifton

April 1992

National Institute of Standards and Technology

Gaithersburg, MD 20899

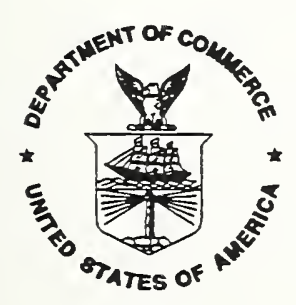

U.S. Department of Commerce

Barbara Hackman Franklin, Secretary

Technology Administration

Robert M. White, Under Secretary for Technology

National Institute of Standards and Technology

John W. Lyons, Director 



\section{ABSTRACT}

The microstructure of mortars with water/solids ratios (w/s) of 0.36 and 0.29 , cured under water at 7,23 , and $40^{\circ} \mathrm{C}$, were studied by scanning electron microscopy and $\mathrm{x}$-ray powder diffractometry. The mortars contained silica fume and a superplasticizer. The degree of hydration and extent of pozzolanic reaction was estimated after quantifying the residual unhydrated cement by image analysis and the mass percent calcium hydroxide by X-ray powder diffraction. Their microstructures were fairly homogeneous in both the bulk paste and at the paste-aggregate transition zone. In all mortars, the outer $250 \mathrm{\mu m}$ was hydrated to about 85 percent and highly microcracked. The degree of hydration decreased rapidly beyond the outer zone to about 69 percent and less microcracking was observed. A temperature effect on the reactivity of silica fume was found.

KEYWORDS: Cement; curing temperature; high-performance concrete; hydration; microstructure; mortar; scanning electron microscopy; silica fume; X-ray powder diffraction. 
Table of Contents

Page

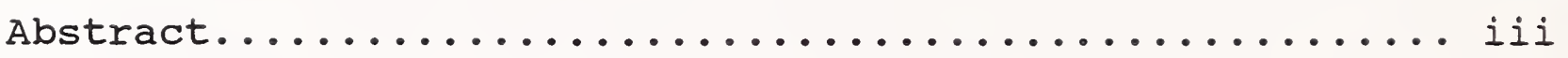

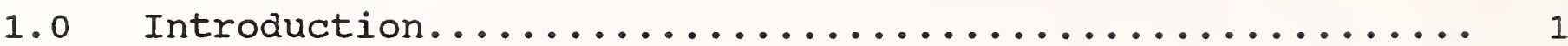

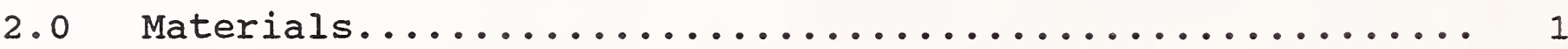

3.0 Analytical Methods.......................... 2

3.1 Sample Preparation for SEM Analysis.......... 3

4.0 Microstructural Observations.................. 4

4.1 Air Content.......................... 4

4.2 Paste Microstructure..................... 4

4.3 Outer Perimeter Microstructure.............. 10

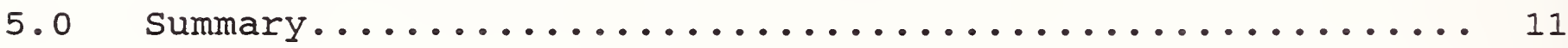

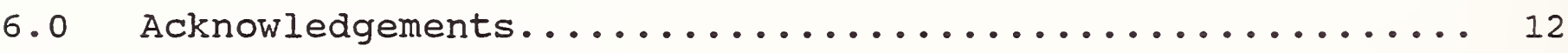

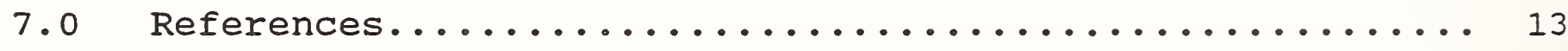


List of Tables

page

Table 1. Water-to cementitious solids ratio, curing, equivalent ages (EA) at $23^{\circ} \mathrm{C}$ for sampling, and strengths for

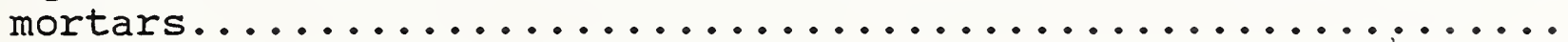

Table 2. Degree of hydration ( $\alpha$ ) and pozzolanic reaction (PR) as determined by SEM and QXRD. CH-T is the theoretical mass of calcium hydroxide based on the degree of hydration, CH-QXRD is the actual mass of calcium hydroxide measured by QXRD, and $\mathrm{CH}-\mathrm{SF}$ is the maximum potential consumption of calcium

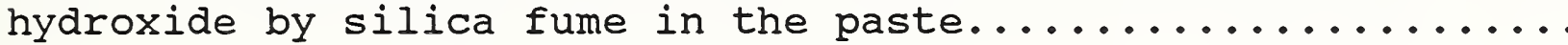

List of Figures

Figure 1. Microstructure of paste in a 28 day old concrete $(w / c=0.45)$ showing unhydrated cement $(A)$, calcium hydroxide $(\mathrm{CH})$, calcium-silicate-hydrate ( $\mathrm{CSH})$, monosulfoaluminate

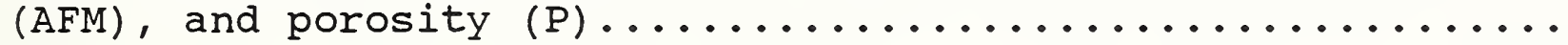

Figure 2. BE micrographs of $7^{\circ} \mathrm{C}$-cured mortar 602 (a) at $0.29 \mathrm{w} / \mathrm{s}$ and 544 (b) at $0.36 \mathrm{w} / \mathrm{s}$ with unhydrated cement (A), calcium hydroxide $(\mathrm{CH})$, calcium-silicate-hydrate $(\mathrm{CSH})$, aggregate (AG), microcracks (MC), and porosity

(P) .... 6

Figure 3. BE micrographs of $23^{\circ} \mathrm{C}$-cured mortar 437 (a) at $0.29 \mathrm{w} / \mathrm{s}$ and 470 (b) at $0.36 \mathrm{w} / \mathrm{s}$ with unhydrated cement (A), calcium hydroxide $(\mathrm{CH})$, calcium-silicate-hydrate $(\mathrm{CSH})$, aggregate $(\mathrm{AG})$, and porosity $(\mathrm{P}) \ldots \ldots \ldots \ldots \ldots \ldots \ldots \ldots . . .$.

Figure 4. BE micrographs of $40^{\circ} \mathrm{C}$-cured mortar 717 (a) at $0.29 \mathrm{w} / \mathrm{s}$ and 818 (b) at $0.36 \mathrm{w} / \mathrm{s}$ with unhydrated cement (A), calcium hydroxide $(\mathrm{CH})$, calcium-silicate-hydrate $(\mathrm{CSH})$, aggregate (AG), microcracks (MC), and porosity

(P) $\ldots .8$

Figure 5. Typical mortar microstructure of the outer perimeter at (a) low and (b) higher magnifications. A skin of calcium hydroxide $(\mathrm{CH})$ coats the outside surface and a zone of maximum hydration, $\mathrm{CH}$-depleted, microcracked paste (MC) extends into the cube for about $200 \mu \mathrm{m}$. Other features include fully hydrated grain relics (HCG), unhydrated $C_{4} A F$ and $C_{3} A(A)$, $\mathrm{CSH}$, aggregate $(\mathrm{AG})$, and porosity $(\mathrm{P}) \ldots \ldots \ldots \ldots \ldots \ldots \ldots \ldots$ 

High-performance concrete (HPC) is a new class of concrete with superior mechanical and durability properties [1]. Because of the potential benefits of HPC to the US construction industry, the National Institute of Standards and Technology (NIST) is planning the development of a nationally-coordinated program aimed at providing a technical basis for exploiting the potential of HPC $[1,2]$. Also, NIST has undertaken a research program to study the properties of, and the factors affecting the use and performance of, HPC. The first part of the research program involved determining if the compressive strength development of HPC could be described by the maturity concept used for conventional concrete [3]. In the study, mortar cubes with low waterto-cementitious-solids (w/s) ratios were cured at 7,23 , and $40^{\circ} \mathrm{C}$, in saturated lime water, and their compressive strengths measured at different ages.

HPC is usually composed of portland cement with a mineral admixture such as silica fume or ground blast furnace slag, has a low water-tocementitious solids ratio (w/s less than 0.4 and as low as 0.22 ), and utilizes a superplasticizer. A superplasticizer is used so that a low $\mathrm{w} / \mathrm{s}$, workable concrete is produced. Because of the low w/s ratio and reduced porosity, there is insufficient water and internal space for complete hydration of the cementitious material. In this report, the scanning electron microscope (SEM) was used to examine microstructural features of the mortars and quantitative $\mathrm{X}$-ray powder diffraction (QXRD) was used to measure the mass percent of calcium hydroxide in the cement paste. These analyses included observation of the bulk paste microstructure, the paste/aggregate interfacial zone, estimating the degree of hydration by quantifying the residual unhydrated cement, and estimation of the extent of pozzolanic reactions for the different cure temperatures.

\subsection{MATERIALS}

All mortars were prepared with an ASTM Type I portland cement, silica fume slurry with 48 percent solids, graded ottawa sand meeting the requirements of ASTM C 778, and a superplasticizer. The silica fume slurry was added as a ten percent by mass replacement of cement. Water-to-cementitious solids (cement + silica fume) ratios of 0.36 and 0.29 were used. The mix proportions are given in Table 1 [3].

The mortars were prepared by the following procedures. First, the silica fume slurry was passed through a $0.30 \mathrm{~mm}$ (No. 50) sieve to disaggregate the larger agglomerates of silica fume and was blended with mixing water. Cement was then added to the slurry followed by the sand and the superplasticizer. The paste was mixed with a large paddle mixer. The mortars were placed into $50-\mathrm{mm}$ cube molds, in two equal layers, and were consolidated by rodding with a small rubber tamper. The cast cubes were covered with sheets of rigid plastic and placed in saturated lime water baths at the specified curing temperature of $7^{\circ}, 23^{\circ}$, or $40^{\circ} \mathrm{C}$. 
Table 1. Water-to-cementitious solids ratio, curing, equivalent ages (EA) at $23^{\circ} \mathrm{C}$ for sampling, and strengths for mortars.

\begin{tabular}{||c|c|c|c|c|c|}
\hline \hline Mix & $\begin{array}{c}\text { Water/ } \\
\text { Solids }\end{array}$ & $\begin{array}{c}\text { Cure } \\
\text { Temp }\end{array}$ & $\begin{array}{c}\text { EA- } \\
\text { Microstructure }\end{array}$ & $\begin{array}{c}\text { EA- } \\
\text { Strength }\end{array}$ & $\begin{array}{c}\text { Strength } \\
\text { (Mpa) }\end{array}$ \\
\hline 602 & 0.285 & $7^{\circ} \mathrm{C}$ & 91 & 56 & 110 \\
\hline 544 & 0.360 & $7^{\circ} \mathrm{C}$ & 37 & 46 & 82 \\
\hline 437 & 0.285 & $23^{\circ} \mathrm{C}$ & 95 & 56 & 117 \\
\hline 470 & 0.360 & $23^{\circ} \mathrm{C}$ & 91 & 56 & 89 \\
\hline 717 & 0.285 & $40^{\circ} \mathrm{C}$ & 116 & 73 & 117 \\
\hline 818 & 0.360 & $40^{\circ} \mathrm{C}$ & 125 & 92 & 85 \\
\hline
\end{tabular}

After 24 hours the cubes were removed from their molds and returned to the saturated lime water baths. Cubes from each batch were tested for compressive strength at specified ages.

\subsection{ANALYTICAL METHODS}

Backscattered electron (BE) imaging, energy dispersive X-ray imaging (XRI) and energy dispersive X-ray microanalysis (XRM) were used to examine the microstructure of the specimens. X-ray powder diffraction was used for phase composition analysis.

Polished sections were used for examination and image analysis of microstructures. The intensity of the backscattered electron signal is proportional to the average atomic number of the material. For mortars, the unhydrated cement grains appear brightest, followed by $\mathrm{CH}$, calcium silicate hydrate (CSH), while resin-filled voids are dark [Figure 1]. Phase identification is made by deduction from the relative grey level, the phase morphology, and the composition as measured by XRM. For example, monosulfoaluminate (AFm) occurs as relatively large masses (1 $\mu \mathrm{m}-5 \mu \mathrm{m})$, of slightly darker grey level, exhibiting a platy parting, and relatively high sulfur content.

Scrivener et al. [8] showed that analysis of SEM images can be used to quantify the degree of hydration of cement. The degree of hydration was estimated by collecting about 25 fields each covering a $4.8 \mathrm{~mm}^{2}$ area, segmenting the image based on grey level, and measuring the area percent unhydrated cement in the cement paste. The initial cement, silica fume, and water contents were converted to volume fractions by dividing the mass fraction by it's density. The degree of hydration $(\alpha)$ is calculated using eqn. 1:

$$
\alpha=1-\frac{\text { Unhydrated Cement }}{\text { Initial Cement }}
$$


Quantitative X-ray powder diffraction was used to determine the amount of calcium hydroxide ( $\mathrm{CH})$ and quartz in powdered samples of each mortar. The Reference Intensity Ratio method [5] was used with NIST SRM 640, silicon as the internal standard. The $\mathrm{CH}$ values were calculated as mass percent of the cement paste after the sand content (quartz) had been subtracted. Qualitative analysis for identification of calcium hydroxide in the outer surfaces of mortars 437 and 470 was carried out by $x$-ray diffraction. The outer surface (about $4 \mathrm{~mm}$ ) was sectioned from the cube and the $\mathrm{CH}$ skin precipitated during immersion in lime water was removed by careful sanding. The exterior face of the slabs were mounted in the diffractometer for analysis. Beam penetration for copper $\mathrm{K} \alpha$ radiation in quartz is about $50 \mu \mathrm{m}$ [6] and in porous calcium silicates probably would not exceed $100 \mu \mathrm{m}$.

\subsection{Sample Preparation for SEM Analysis}

The cubes were marked for orientation (top, outer surface) and were trimmed to approximately $30 \mathrm{~mm}$ by $50 \mathrm{~mm}$. Thin (1 mm) wafers were sampled from each cube using a low-speed diamond wafering saw in a manner that enabled observation of the microstructure from the outside to the center of the cube.

The wafers were potted using a procedure developed at NIST where the pore solution is replaced by ethanol and the ethanol is then replaced by an ultra-low viscosity embedding resin ${ }^{2}$ [4]. This procedure stops hydration, replaces the pore solution with alcohol and the alcohol with resin, thereby potting the sample with minimal drying shrinkage cracking. After the resin is cured, the potted sample is ground to expose the mortar and then polished on a lap wheel with a low-nap cloth and a series of $6,3,1$, and $0.25 \mu \mathrm{m}$ diamond pastes. The polished samples are rinsed in ethanol and are coated with a thin (50 $\mathrm{nm})$ layer of carbon to prevent charging in the SEM.

In properly polished sections, the phases of the unhydrated cement grains are visible. Quartz sand aggregate will appear darker than the $\mathrm{CSH}$, while any calcium carbonate will appear at about the same grey level as CSH, and will be difficult to separate from the bulk paste. $\mathrm{CH}$ morphologies include prismatic $\mathrm{CH}$, which often exhibits cleavage partings, blocky $\mathrm{CH}$ (no distinct shape), and finely disseminated $\mathrm{CH}$ which may not be resolvable in the $\mathrm{BE}$ image.

${ }^{1}$ Isomet, Buehler Ltd., Chicago, Illinois

${ }^{2}$ L.R. White, Hard Grade. Available from most electron microscopy supply dealers. 


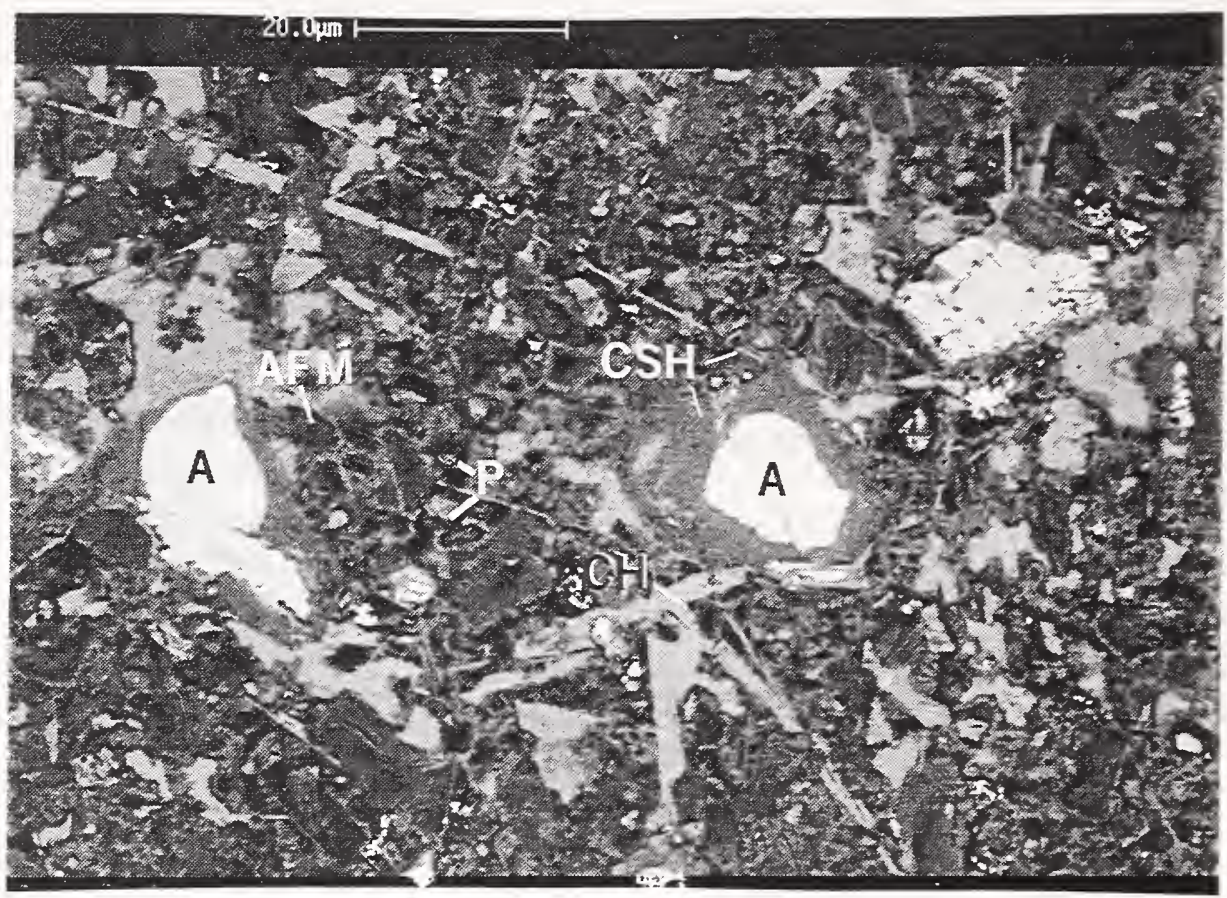

Figure 1. Microstructure of paste in a 28 day old concrete ( $/ \mathrm{c}=$ 0.45 ) showing unhydrated cement (A), calcium hydroxide (CH), calcium silicate hydrate (CSH), monoslufoaluminate (AFM), and porosity (P).

The bulk of the hydrated cement paste is composed of CSH, a complex mixture of fine-grained (micrometer to nanometer size range) calcium silicate hydrates, and other hydrates such as ettringite, thaumasite, monosulfoaluminate, and hydrogarnet, all of which may be finely intermixed [7]. The compositions and degrees of crystallinity of these phases vary, making X-ray powder diffraction identification difficult. The grain sizes of these phases are often at or below the limits of spatial and contrast resolution in the BE detector..

\subsection{MICROSTRUCTURAL OBSERVATIONS}

\subsection{Air content}

Air entrapped during mixing was measured by analysis of lowmagnification (15x) $\mathrm{BE}$ images. The $0.36 \mathrm{w} / \mathrm{s}$ mortars (Table 2) averaged twice $(8 \%)$ the entrapped air contents of the $0.29 \mathrm{w} / \mathrm{s}$ mortars (4\%) with the largest voids approaching $2 \mathrm{~mm}$ in diameter. Entrapped air voids partially filled with $\mathrm{CH}$ were common in these mortars.

\subsection{Paste Microstructure}

A comparison of the microstructure change for a paste with a w/C = 0.45 shown in Fig. 1 with the microstructures shown in Figs. 2 to 4 shows the distinct change with the addition of silica fume and lowering of the w/s ratio. Generally the overall microstructures are much more dense and uniform than that in Fig. 1. A simple way to compare the pastes is to examine the rim of dense CSH enveloping the unhydrated grain and the porous CSH of the matrix of the paste in Fig. 1. These rims of dense $\mathrm{CSH}$ are much less apparent in the mortars of this study. 
Silica fume is much finer than cement and is believed to alter the microstructure of a paste by a number of mechanisms as suggested by Taylor [7]. First, because of its small particle size, it acts as a filler by occupying voids between the cement particles. Silica fume also provides many potential nucleation sites for precipitation of CSH. Finally, silica fume is pozzolanic, reacting with $\mathrm{CH}$ to form additional CSH.

In mortars and concretes without silica fume, the paste/aggregate interfacial zones are considered weak points in the microstructure. These interfacial regions, extending about $100 \mu \mathrm{m}$ from the aggregate, are characterized by high porosity, relics of completely hydrated cement grains, low concentrations of unhydrated cement grains, and possibly greater concentrations of $\mathrm{CH}$ at the paste/aggregate boundary [8].

The mortars in this study exhibit a uniform, dense paste adjacent to the aggregate surface. Pore microstructure appears much finer in these images although some large $(5 \mu \mathrm{m}-15 \mu \mathrm{m})$ pores are common. Although difficult to discern in the micrographs, calcium hydroxide was observed around the paste/aggregate boundary in the $7^{\circ}$ and $23^{\circ}-$ cured mortars (Figs. 2 and 3 ) but not in the $40^{\circ}$-cured mortars (Fig. 4). However, there does not appear to be high concentrations of $\mathrm{CH}$ in the paste/aggregate interfacial zone in any of these mortars. Some local high porosity regions may be the result of water bleeding during consolidation. Scrivener et al. [8] noted that silica fume pastes have similar porosities to non-silica fume pastes, although permeabilities of the silica fume pastes are significantly lower. They felt that improved bonding of paste and aggregate, as seen in the more uniform paste/aggregate interfacial zone, accounts for most of the strength increase and permeability reduction in silica fume concretes.

The morphology of calcium hydroxide appears to be influenced by both the w/s ratio and the curing temperature. Prismatic crystals and blocky $\mathrm{CH}$ are readily apparent in the $7^{\circ} \mathrm{C}$-cured, $0.36 \mathrm{~W} / \mathrm{s}$ mortar, whereas blocky $\mathrm{CH}$ predominates in the $0.29 \mathrm{w} / \mathrm{s}$ mortar (Fig. 2). The lower curing temperature may have allowed time and provided room for larger $\mathrm{CH}$ crystals to form. Calcium hydroxide occurrence in the $23^{\circ} \mathrm{C}-$ cured mortars, while not as common, mirrors the $7^{\circ} \mathrm{C}$-cured mortars, with the $0.36 \mathrm{w} / \mathrm{s}$ mortar containing more prismatic $\mathrm{CH}$ crystals, whereas blocky $\mathrm{CH}$ predominates in the $.29 \mathrm{w} / \mathrm{s}$ mortar. Blocky $\mathrm{CH}$ with crystals up to $25 \mu \mathrm{m}$ in diameter are common in the $40^{\circ} \mathrm{C}$-cured mortars, while $\mathrm{CH}$ was not observed in their paste/aggregate interfacial areas. Kjellsen, et al. [9] observed changes in $\mathrm{CH}$ morphologies in plain cement pastes with well-formed, elongated crystals forming in specimens cured at low temperatures and blocky $\mathrm{CH}$ forming at higher curing temperatures. 


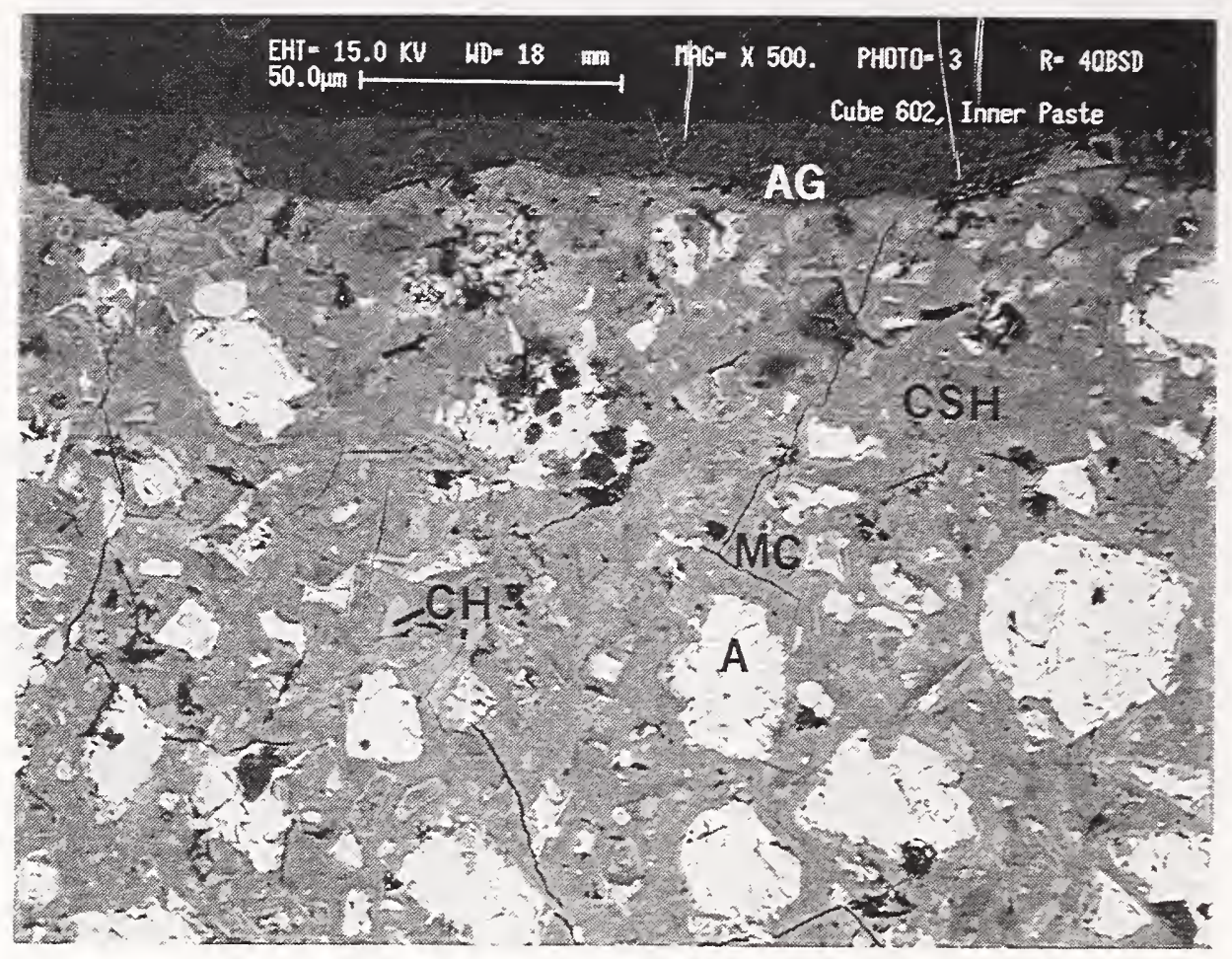

(a)

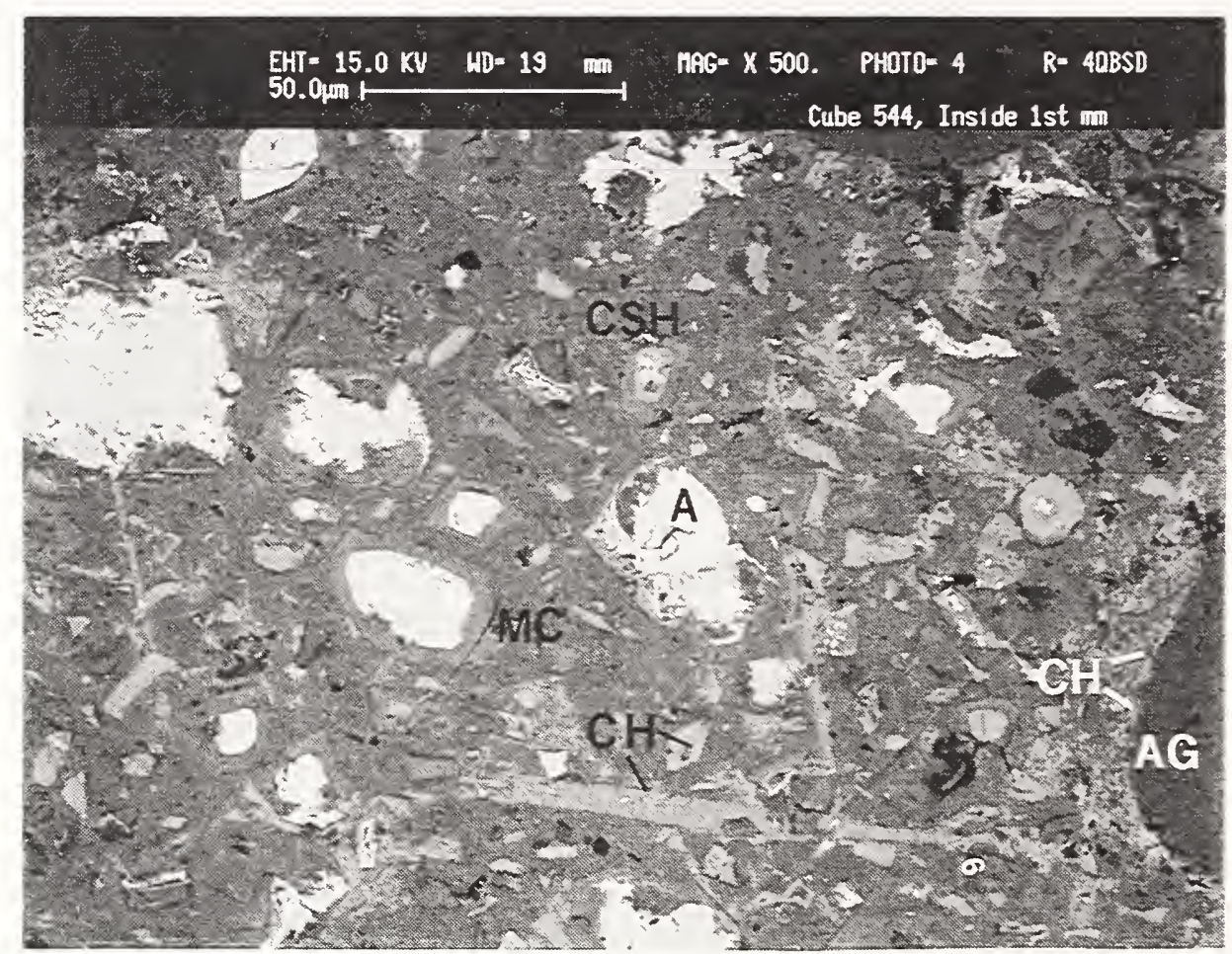

(b)

Figure 2. BE micrographs of $7^{\circ} \mathrm{C}$ cured mortar 602 (a) at $0.29 \mathrm{w} / \mathrm{s}$ and 544 (b) at $0.36 \mathrm{w} / \mathrm{s}$ with unhydrated cement (A), calcium hydroxide $(\mathrm{CH})$, calcium-silicate-hydrate (CSH), aggregate (AG), microcracks (MC), and porosity (P). 


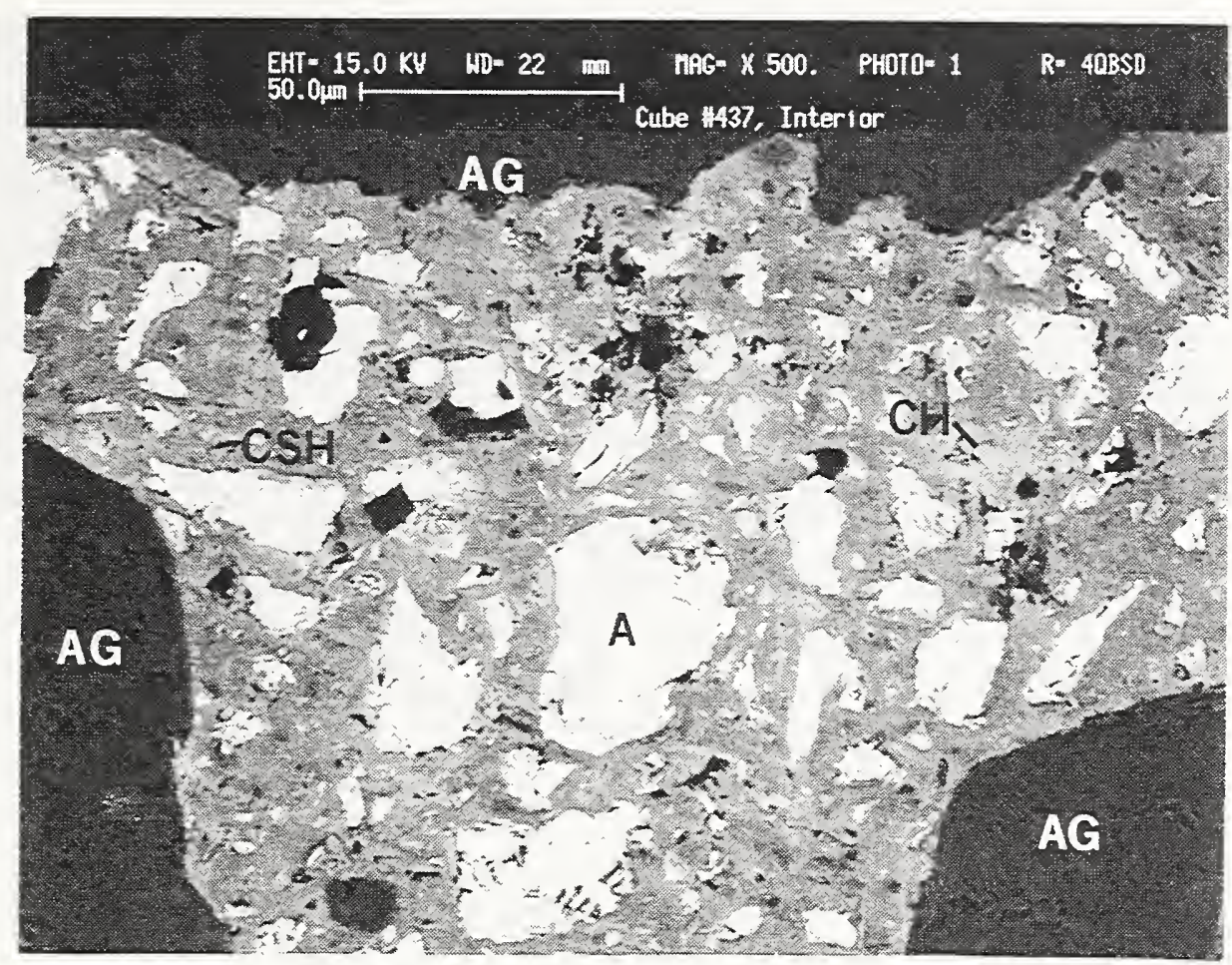

(a)

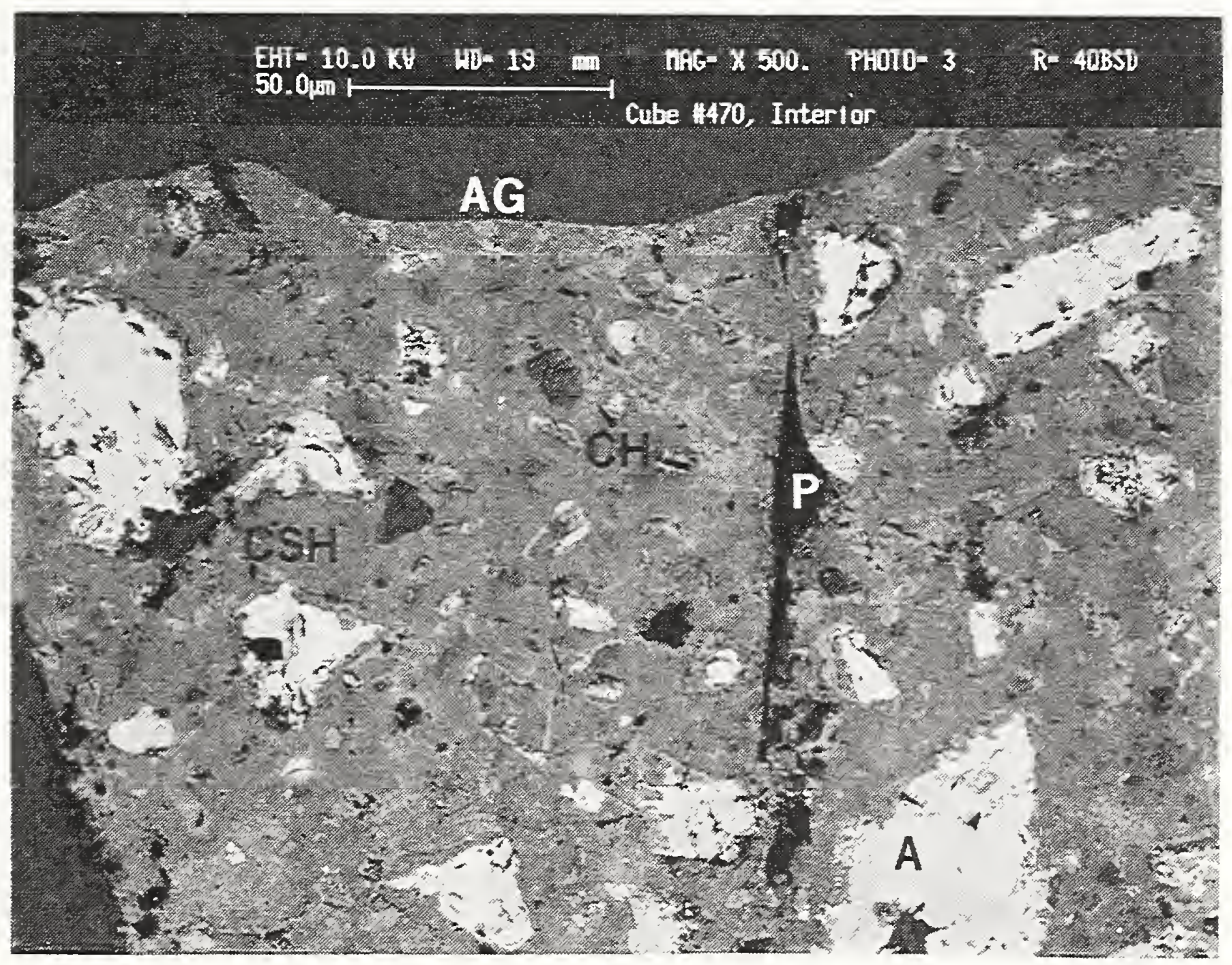

(b)

Figure 3. BE micrographs of $23^{\circ} \mathrm{C}$ cured mortar 437 (a) at $0.29 \mathrm{w} / \mathrm{s}$ and 470 (b) at $0.36 \mathrm{w} / \mathrm{s}$ with unhydrated cement (A), calcium hydroxide $(\mathrm{CH})$, calcium-silicate-hydrate (CSH), aggregate (AG), and porosity (P) . 


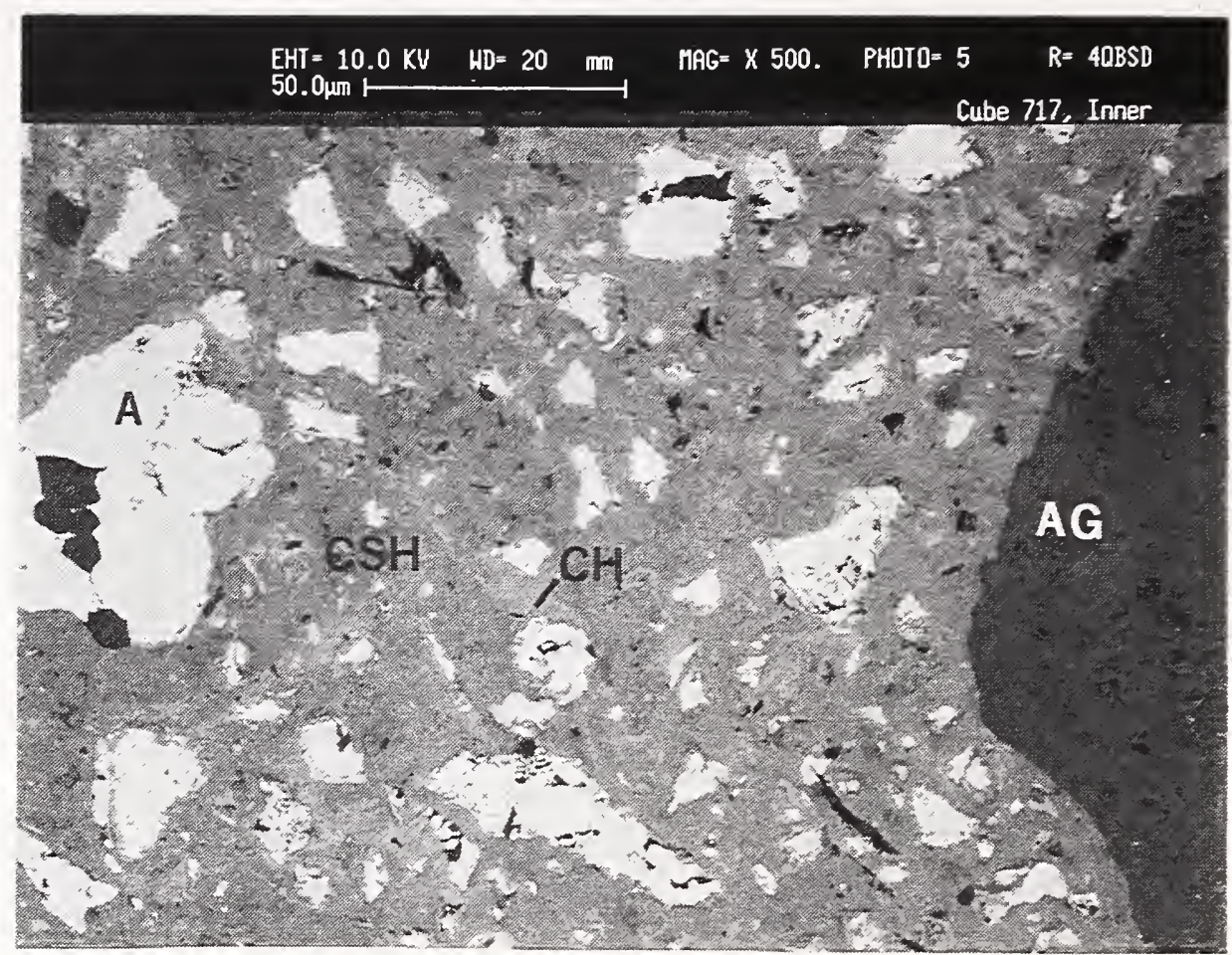

(a)

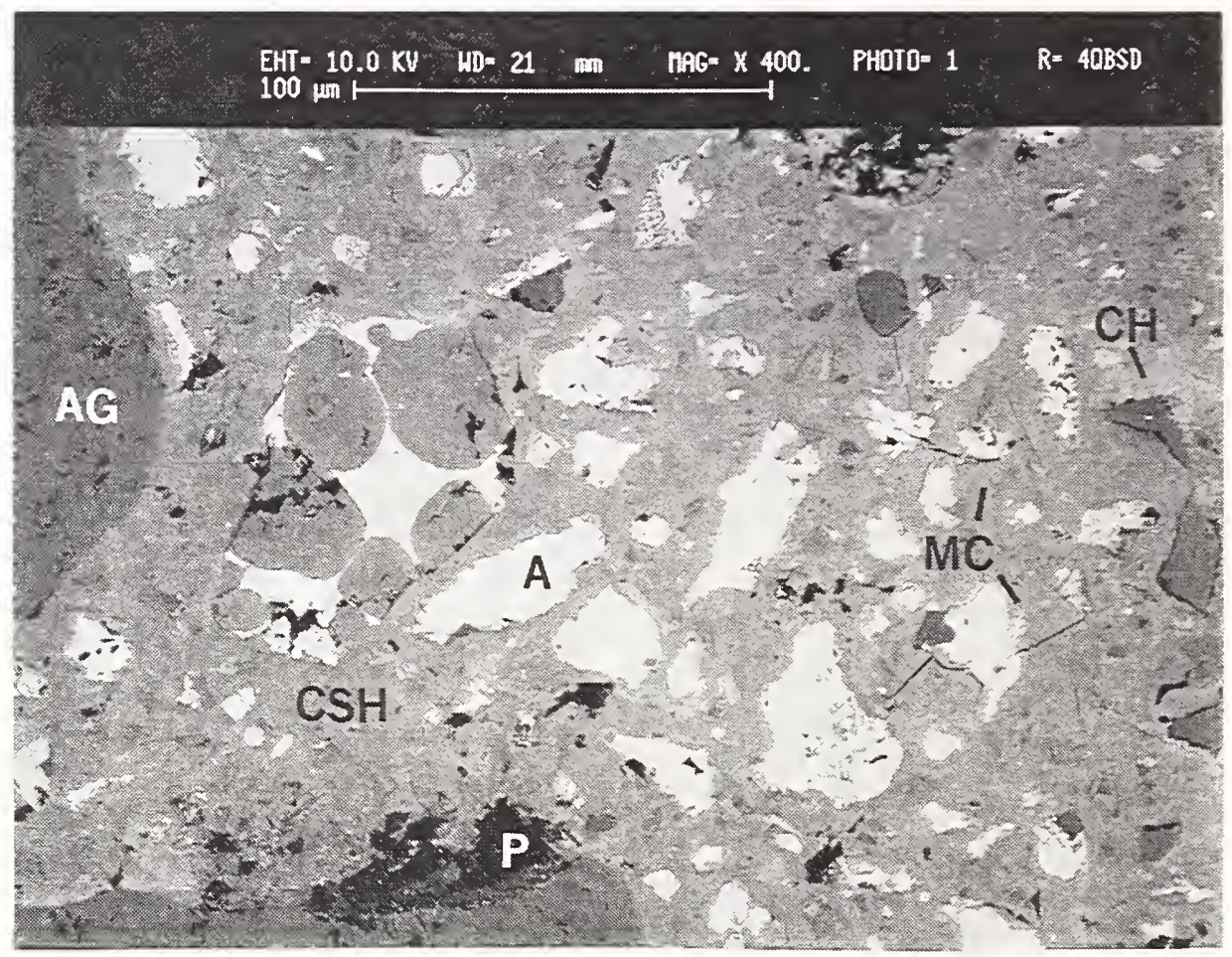

(b)

Figure 4. BE micrographs of $40^{\circ} \mathrm{C}$ cured mortar 717 (a) at $0.29 \mathrm{~W} / \mathrm{s}$ and 818 (b) at $0.36 \mathrm{w} / \mathrm{s}$ with unhydrated cement (A), calcium hydroxide $(\mathrm{CH})$, calcium-silicate-hydrate (CSH), aggregate (AG), microcracks (MC), and porosity (P). 


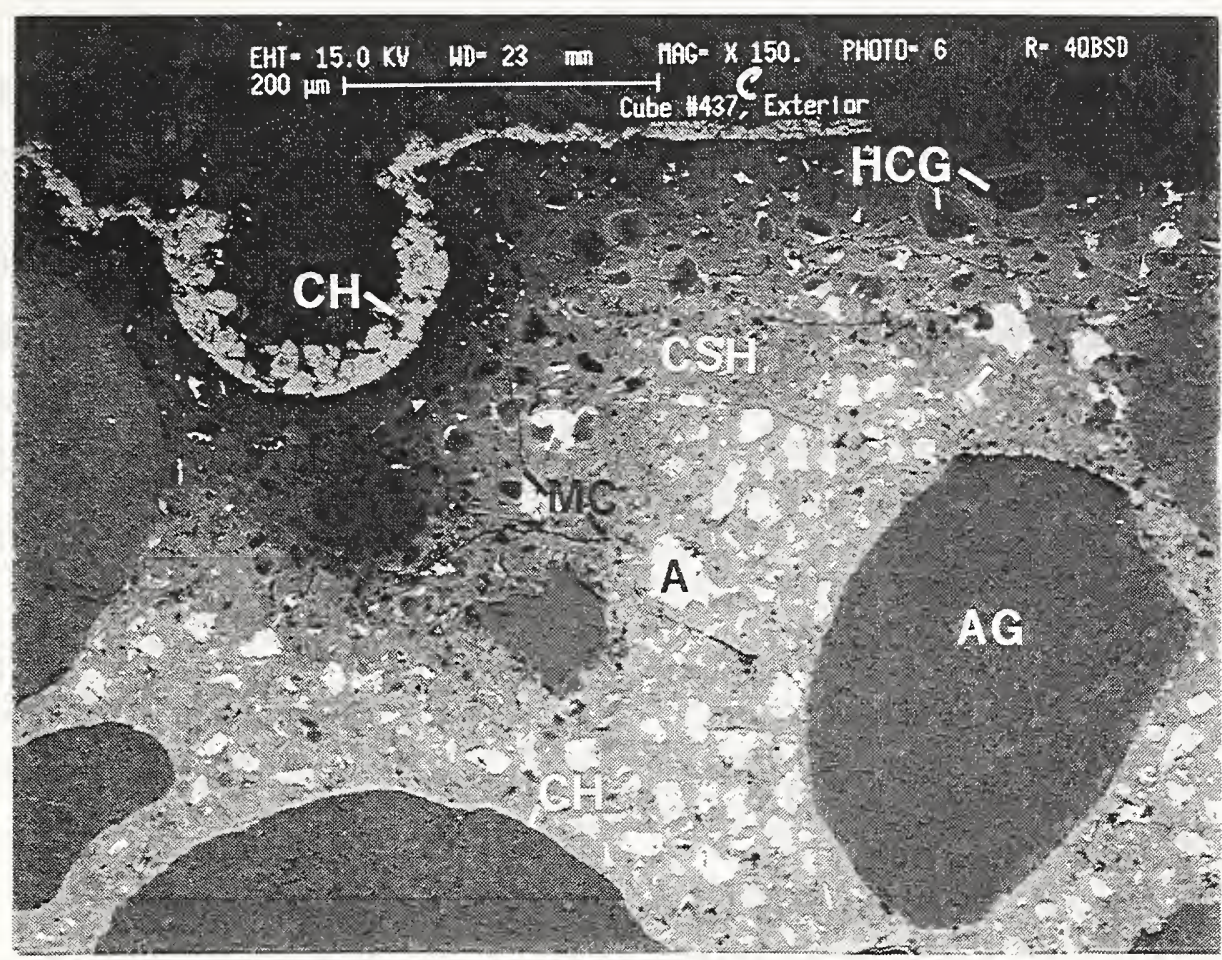

(a)

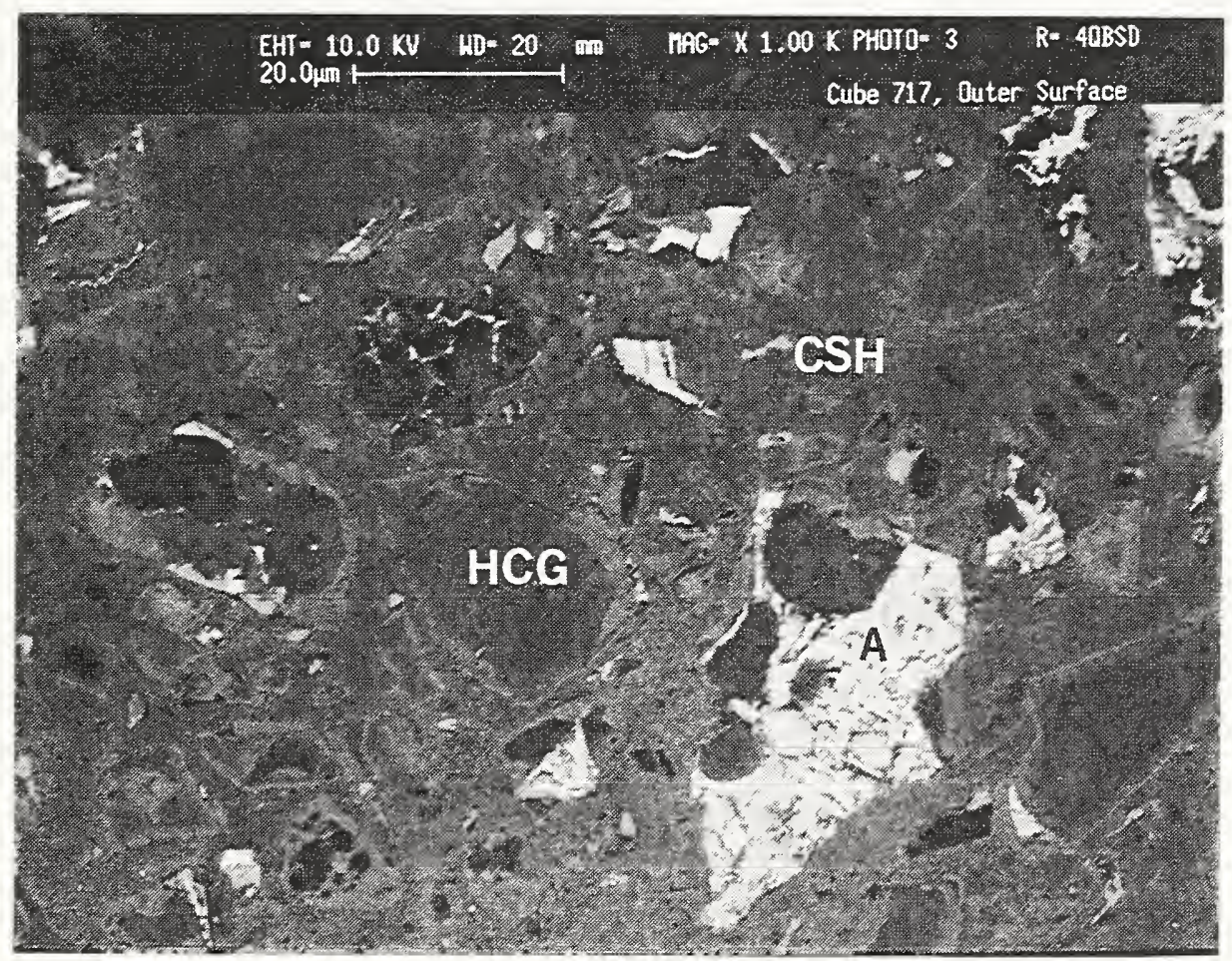

(b)

Figure 5. Typical mortar microstructure of the outer perimeter at (a) low and (b) higher magnifications. A skin of calcium hydroxide (CH) coats the outside surface and a zone of maximum hydration, $\mathrm{CH}-$ depleted, microcracked paste (MC) extends into the cube for about 200 $\mu \mathrm{m}$. Other features include fully hydrated grain relics (HCG), unhydrated $C_{4} A F$ and $C_{3} A(A), C S H$, aggregate $(A G)$, and porosity (P). 
Quantitative X-ray powder diffraction analysis indicated that the $7^{\circ} \mathrm{C}-$ cured mortars contained about twice the amount of $\mathrm{CH}$ as the other mortars. Table 2 shows the mass percent $\mathrm{CH}$ of the mortar as determined by QXRD (CH-QXRD), estimates of theoretical CH production based on the composition of the cement and the degree of hydration determined by image analysis $(\mathrm{CH}-\mathrm{T})$. If we assume that pozzolanic $\mathrm{CSH}$ has a Ca/Si ratio of $1.2,1.5$ grams of $\mathrm{CH}$ should be consumed by 1.0 grams of silica fume. The maximum potential consumption of $\mathrm{CH}$ by pozzolanic reaction with the available silica fume is given in $\mathrm{CH}-\mathrm{SF}$. The extent of pozzolanic reaction (PR) is derived as the ratio of $\mathrm{CH}$ apparently consumed by the pozzolanic reaction to that which theoretically could be consumed if all the silica fume reacted.

The extent of pozzolanic reaction value of 0.39 and 0.46 for the $7^{\circ} \mathrm{C}-$ cured mortars and 0.65 to 0.75 for the $23^{\circ} \mathrm{C}$-cured and $40^{\circ} \mathrm{C}$-cured mortars indicates that the reaction between $\mathrm{CH}$ and silica fume is not as complete for the $7^{\circ} \mathrm{C}$-cured mortars.

\subsection{Outer Perimeter Microstructure}

The outer perimeter of each of the cubes had a band of almost completely hydrated, highly microcracked, possibly higher porosity paste extending about $200 \mu \mathrm{m}$ in from the surface. For example, Figure $5 a$ shows the microstructure for cube $437\left(23^{\circ} \mathrm{C}\right.$-cured, w/s=0.29) where both large and small cement particles have completely hydrated leaving distinct dark, zoned grain relics. The remaining unhydrated material is predominantly ferrite and aluminate enveloped by ferrite. Calcium hydroxide is absent from this outer region in both the BE images and by $x$-ray diffraction analysis of the outer surface. Crumbie et al. [10] observed a lack of $\mathrm{CH}$ in the outer $200 \mu \mathrm{m}$ of 0.40 and 0.60 water/cement ratio concretes, but did not find the increase in degree of hydration or microcracking. They attribute the lack of $\mathrm{CH}$ to leaching and also found that concretes cured in sulfate solution exhibited greater depths of $\mathrm{CH}$ depletion.

The microcracks range in width up to a few micrometers and diminish in abundance at about $0.5 \mathrm{~mm}$ inside the mortar. Microcracking of the paste occurs inside this $0.5 \mathrm{~mm}$ band, but is far less common than in the outer portions. The cracking of the outer surface may have resulted from drying shrinkage and possibly from carbonation shrinkage. $x$-ray diffraction data of a cut slab indicate the presence of vaterite $\left(\mathrm{CaCO}_{3}\right)$ and calcite in the outer surface, suggesting that some of the cracking may be a result of carbonation. 
Table 2. Degree of hydration $(\alpha)$ and pozzolanic reaction (PR) as determined by SEM and QXRD. $\mathrm{CH}-\mathrm{T}$ is the theoretical mass of calcium hydroxide based on the degree of hydration, $\mathrm{CH}-Q X \mathrm{RD}$ is the actual mass of calcium hydroxide by QXRD, and $\mathrm{CH}-\mathrm{SF}$ is the maximum potential consumption of calcium hydroxide by silica fume in the paste.

\begin{tabular}{||c|c|c|c|c|c|c|c|c||}
\hline \hline Mix & W/S & $\begin{array}{c}\text { Cure } \\
\text { Temp }\end{array}$ & $\begin{array}{c}\text { fir } \\
\text { Air }\end{array}$ & $\begin{array}{c}\text { Hydration } \\
(\alpha)\end{array}$ & CH-T & CH-QXRD & CH-SF & PR \\
\hline 602 & 0.29 & $7^{\circ} \mathrm{C}$ & 4.0 & $.68, \pm .05$ & 13.6 & 9.1 & 11.0 & .39 \\
\hline 544 & 0.36 & $7^{\circ} \mathrm{C}$ & 7.5 & $.75, \pm .04$ & 14.2 & 9.1 & 11.0 & .46 \\
\hline 437 & 0.29 & $23^{\circ} \mathrm{C}$ & 3.5 & $.61, \pm .05$ & 12.2 & 4.6 & 11.7 & .65 \\
\hline 470 & 0.36 & $23^{\circ} \mathrm{C}$ & 6.0 & $.74, \pm .06$ & 13.0 & 5.7 & 11.0 & .75 \\
\hline 717 & 0.29 & $40^{\circ} \mathrm{C}$ & 6.0 & $.65, \pm .03$ & 13.0 & 9.1 & 11.7 & .76 \\
\hline 818 & 0.36 & $40^{\circ} \mathrm{C}$ & 8.3 & $.72, \pm .03$ & 13.7 & 5.5 & 11.0 & .75 \\
\hline
\end{tabular}

Processing of the BE images of these mortars showed that the proportion of unhydrated cement increased inward Unhydrated cement was a minimum within the zone of maximum hydration, about the first $250 \mu \mathrm{m}$, and increased rapidly there after. The zone of maximum hydration was found in the outer perimeter, to about $200 \mu \mathrm{m}$ in depth, of these mortars at about 85 percent hydration and decreased rapidly inward.

\subsection{SUMMARY}

1. The mass of calcium hydroxide in $7^{\circ} \mathrm{C}$-cured silica fume mortars was almost twice that of $23^{\circ} \mathrm{C}$-cured and $40^{\circ} \mathrm{C}$-cured mortars. With all mortars hydrated to about the same level (69 percent), the increased mass of $\mathrm{CH}$ indicates a lower extent of pozzolanic reaction with the silica fume in the $7^{\circ} \mathrm{C}$-cured mortars.

2. The low water/solids ratio and the addition of silica fume produced a dense, uniform microstructure and dense CSH paste up to the aggregate. Crystal habit of calcium hydroxide was prismatic in the mortar with $\mathrm{w} / \mathrm{s}=0.36,23^{\circ} \mathrm{C}$ and in both mortars cured at $7^{\circ} \mathrm{C}$. Blocky $\mathrm{CH}$ predominated in both $40^{\circ} \mathrm{C}$ cured mortars.

3. A zone of maximum paste hydration rimmed the exterior surfaces of each specimen with only minor amounts of ferrite and aluminate remaining from the unhydrated cement. Degree of hydration decreased from a high of about 85 percent within the outer $250 \mu \mathrm{m}$ to about 69 percent for the interior paste.

4. Microcracking occurred within the paste, but was most common in an outer maximum hydrated paste layer extending about $250 \mu \mathrm{m}$ into the mortar. The cause of cracking in this layer may be drying shrinkage or possibly carbonation shrinkage. 


\subsection{ACKNOWLEDGEMENTS}

The authors appreciate the review and suggestions of Ken snyder and Nick Carino and thank Dale Bentz for review comments and help in the calculation of the potential compositions and degree of hydration. 
1. "Outline of a National Plan on High-Performance Concrete: Report on the NIST/ACI Workshop, May 16-18, 1990," National Institute of standards and Technology, NISTIR 4465 (December, 1990).

2. N.J. Carino and J.R. Clifton, "High-Performance Concrete: Research Needs to Enhance its Use," Concrete International, vol. 13 (no. 9), pp. 70-76 (1991).

3. N.J. Carino, L.I. Knab, and J.R. Clifton, "Applicability of the Maturity Method to High Performance Concrete." NISTIR in progress.

4. Struble, L.J and Stutzman, P.E., Epoxy Impregnation of Hardened Cement for Microstructural Characterization, Journal of Materials Science Letters, 8, pp. 632-634, 1989.

5. F.H. Chung, "Quantitative Interpretation of X-Ray Powder Diffraction Patterns of Mixtures. I. Matrix-Flushing Method for Quantitative Multicomponent Analysis." Jour. Appl. Cryst., 7, pp. 519525,1974 .

6. D.L. Bish and R.C. Reynolds, "Sample Preparation for X-ray Diffraction," IN, Modern Powder Diffraction, D.L. Bish and J.E. Post, eds., Reviews in Mineralogy, Vol. 20, The Mineralogical society of America, Washington, D.C., pp. 73-99, 1989.

7. Taylor, H.F.W., Cement Chemistry, Academic Press, New York, 475 $\mathrm{pp} ., 1990$.

8. Scrivner, K.L., Bentur, A., and Pratt, P.L., "Quantitative Characterization of the Transition Zone in High Strength Concretes," Advances in Cement Research, Vol. 1, No. 4, October, 1988, pp. 230237 .

9. Kjellsen, K.O., Detwiler, R.J., and Gjørv, O.E., "Development of Microstructures in Plain Cement Pastes Hydrated at Different Temperatures," Cement and Concrete Research, Vol. 21, pp. 179-189, 1991.

10. Crumbie, A.K., Scrivener, K.L, and Pratt, P.L., The Relationship Between the Porosity and Permeability of the Surface Layer of Concrete and the Ingress of Aggressive Ions, Mat. Res. Soc. Symp. Proc. Vol. 137 , pp. 279-284, 1989. 



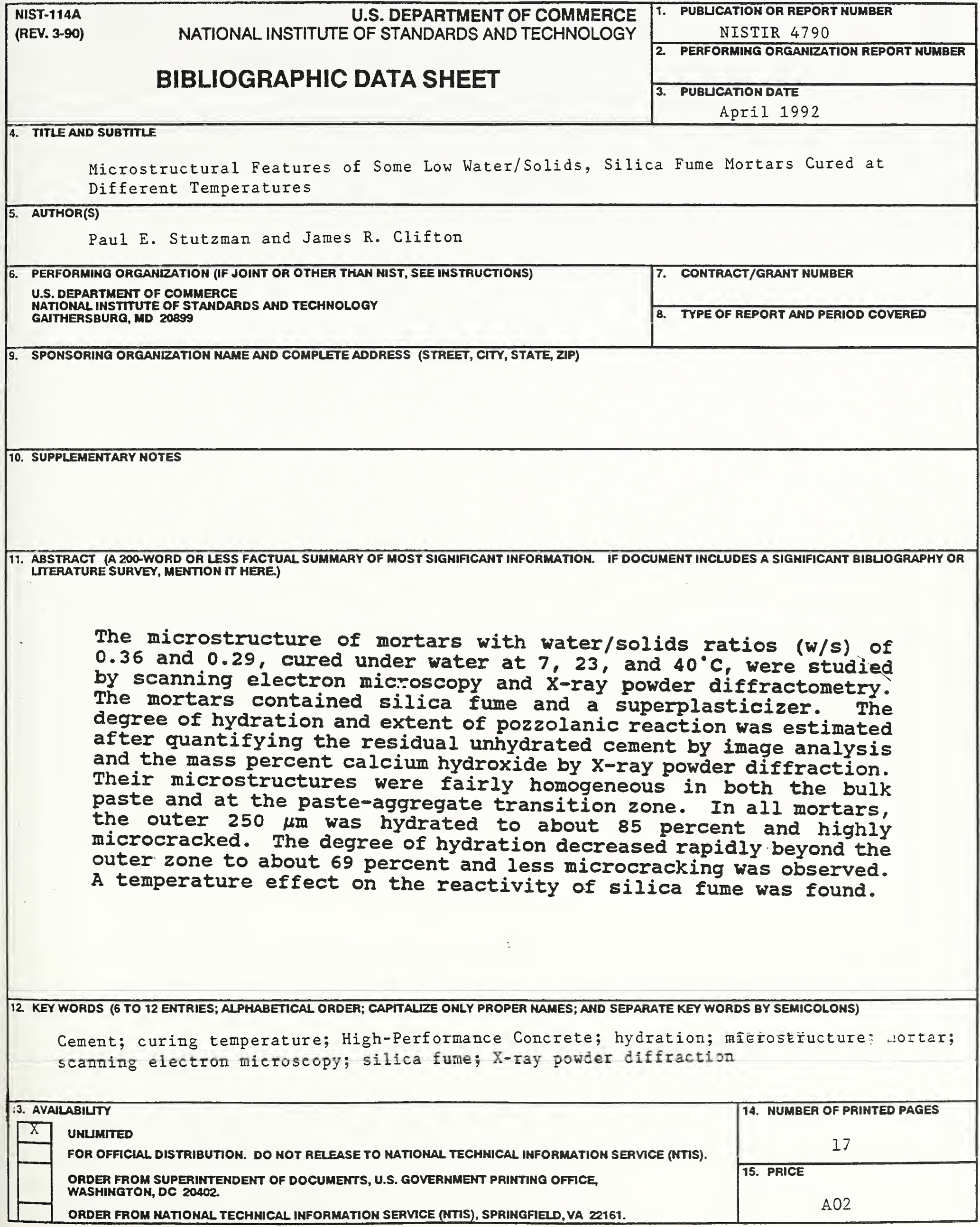




